\title{
Perception of the learning strategies and the learning styles among first year medical students: A cross sectional survey
}

\author{
Vipula Rasanga Bataduwaarachchi ${ }^{1}$, Muditha Madhuwanthi Dissanayake ${ }^{2}$, \\ Sharmila Thillainathan ${ }^{3}$, Rohan Wass Jayasekara ${ }^{4}$
}

\begin{abstract}
Objectives: This paper investigates the perceptions of the current teaching strategies among first year medical students. It further assessed the predominant learning style preferences using the VARK (Visual, Auditory, Reading/Writing and Kinesthetic) questionnaire and the gender differences for learning style preferences.

Methods: This study was conducted among the first year medical students in the Faculty of Medicine, University of Colombo $(n=192)$ and descriptive cross sectional design was adopted. Data was collected using a self-administered multiple choice questionnaire. Frequencies were calculated followed by cross-tabulations to generate descriptive statistics and analyzed with Chi Square distribution test.

Results: Majority of the students found lectures and small group activities as useful learning experiences most of the time; $60.4 \%$ and $47.4 \%$ respectively. The multimodal preference was commoner, $59.8 \%(n=115)$ than the unimodal preference, $40.2 \% \quad(n=77)$. Among the unimodal learners, the majority preferred aural modality, $55.8 \%(n=43)$. Bimodal preference was the most common among multimodal learners, $31.2 \%(\mathrm{~N}=60)$. Learning styles did not significantly differ between male and female students $(p=0.115, n=192)$.

Conclusions: To facilitate multimodal learning, combination of teaching techniques should be employed. Active learning should be further encouraged using a variety of learning tools such as video clips, computer simulations and interactive models.
\end{abstract}

Keywords: learning strategies, VARK style, gender

\section{Introduction}

A thorough understanding of students' learning style in higher education is useful for curriculum development, implementation of different teaching methods and student assessments (Tuan, 2005). Obviously, it is important to understand the characteristics of

\footnotetext{
${ }^{1}$ MBBS

${ }^{2}$ MBBS, MD (Opth)

${ }^{3} \mathrm{MBBS}, \mathrm{PhD}$ (Newcastle)

${ }^{4}$ M.I.Biol (UK), C.Biol.(UK)

Corresponding author:

Dr. Vipula Bataduwaarachchi

Department of Anatomy,

Faculty of Medicine,

University of Colombo,

Kynsey Rd.,

No. 271, Colombo 8

Sri Lanka.
}

the learners to become effective teachers (Gudmundsdottir, 1987). On the other hand, medical students represent a broad spectrum in terms of age, experience, culture, ethnicity, and the level of preparedness. This diversity presents a challenge for medical educators to fulfill the educational needs of all students. Though medical schools pay considerable attention to the development of the curriculum content and the organization of teaching and assessments of students, little attention is given to the impact of these activities on the learning styles of the students. It has been found that the motivation and performance of the students are positively correlated with the instructions that are adapted to their predominant learning preferences (Miller, 2001). Furthermore, the transition from secondary education to undergraduate medical education may be difficult because of the increase in the subject content, change in 
teaching methods and complexity of assessments. Learning style is defined as the composite of characteristic cognitive, affective and physiological characters that serve as relatively stable indicators of how a learner perceives, interacts with and responds to the learning environment (Keefe, 1987). Researchers have focused on various learning style preferences over the years and many different learning styles have been described (Coffield, 2004). One characterization of learning styles is to define the learners' preferred mode of learning in term of the sensory modality by which, they prefer to take in information; Visual (V), Auditory (A), Reading/writing (R) and Kinesthetic (K) (Fleming, 1995; Lujan, 2006). Although learners can use all of these sensory modalities, one mode is often dominant and preferred (Coffield, 2004). For example, visual learners learn through diagrams and symbolic devices such as graphs, flow charts and hierarchies. Auditory learners prefer listening, interacting with others and discussing material. Reading/writing learners learn through interaction with textual contents such as books and notes, whereas kinesthetic learners learn through touching or manipulating objects or material.

Some individuals have a strong single learning preference (unimodal), but others have two or more preferences (multimodal). These categorizations represent only a basic description of the complex manner in which students perceive process and recall information.

In Sri Lanka, the secondary education is mostly a teacher oriented learning process. The Faculty of Medicine, Colombo being the second oldest medical school in South Asia has adopted a more student oriented and problem based curriculum. A wide variety of teaching methods are employed in the faculty including lectures, seminars/symposia, Small Group Activities (SGA), answering sessions, Problem Based Learning Sessions (PBLS) and practicals. Students who score high marks at a very competitive Advanced Level examination are selected into the medical faculty. But, often they are encouraged to 'learn how to learn' in the faculty.

The objective of this study was to assess the perceptions of students about the current teaching strategies. Furthermore, this study was aimed at assessing the predominant learning styles of the first year medical students using the VARK questionnaire
(Fleming, 2001). Gender is known to influence the student learning style (Honigsfeld, 2001) and almost equal numbers entered the faculty annually. Although, previously no significant difference has been reported among gender (Slater, 2007), we addressed the question among our students.

\section{Methods}

This study was conducted among the first year medical students in the Faculty of Medicine, University of Colombo. To meet the objectives, a descriptive cross sectional design was adopted and a questionnaire was developed for data collection. It consisted of two sections. The first section focused on obtaining feedback on their experiences on lectures and Small Group Activities (SGA) and to assess whether students can integrate previous and current knowledge. Some of the relevant statements in the questionnaire were taken from a study conducted in Australia (MeechanAndrews, 2009). For each question, students were given a Likert scale, to select one of the five options (True none of the time/ True little of the time/ True half of the time/ True most of the time/ True all of the time). The second section consisted of VARK test to determine the preferred learning style of individuals devised by Neil Fleming, Lincolin University, New Zealand. We selected this due to its wide use in the field of education, specially the usage in studies among health profession students. It is a self-administered multiple choice questionnaire consisting of sixteen questions which identify the preferences of individuals for particular modes of information presentation. Background information is available on the internet from the VARK homepage (Fleming, 2010). The questionnaire also provided opportunity for any additional comments at the end.

At the beginning, students were informed that the completion of the questionnaire was voluntary and anonymous. The questionnaires were distributed to the students during an afternoon learning session of their first term by a research assistant and they were given 20 minutes to complete it. The data were analyzed using the Statistical Package for Social Sciences (SPSS) version 17, initially using frequencies followed by crosstabulations to generate descriptive statistics. Statistical analysis was conducted using the Chi Square distribution test. Ethical approval for this study was obtained from the Ethics Review Committee (ERC) of the Faculty of Medicine, University of Colombo. 


\section{Results}

Out of 197 questionnaires distributed, 5 incomplete ones were removed from the analysis. Overall response rate was $97.46 \%$ Of the 192 sample subjects, 112 (58.34\%) were male and $80(41.67 \%)$ were female. Hundred and eighty $(93.75 \%)$ of them were Sri Lankan students, whereas 12 (6.25\%) were Bhutanese students. Among the Sri Lankan students Sinhalese, Tamils and Malay Moors were represented as 159 (88.34\%), 14 $(7.78 \%)$ and $7(3.88 \%)$ respectively.

\section{Perception of learning strategies}

Perception of learning strategies were assessed using Likert scale for each question, to select one of the five options (True none of the time/ True little of the time/ True half of the time/ True most of the time/ True all of the time). Majority of the students found lectures and Small Group Activities as useful learning experiences most of the time; $60.4 \%$ and $47.4 \%$ half of the time. Interestingly, $20.3 \%$ said the Small Group Activities were useful all of the time compared to lectures and only $10.9 \%$ (for most of the time) responded as so. However, the majority of the students accepted new ideas were introduced in lectures $(49 \%)$, new ideas were helpful to understand the subject matter in text books $(55.2 \%)$, and new ideas were useful for Small Group Activities (49.5\%).

Favourable responses were observed for the statement on Small Group Activities saying that they allow students to interact with other students; similar $41.1 \%$ responded, at most of the time and at all of the time. Although 39.1\% of the students agreed that they get feedback during the Small Group Activities most of the time, $38 \%$ of the students said it happened only half of the time. The majority $43.8 \%$ agreed that they were allowed to verbally demonstrate their understanding during the Small Group Activities most of the time. Almost more than half of the students $50.5 \%$ agreed that Small Group Activities provided an insight when reading textbooks most of the time.

Generally, responses for the statements on integration of knowledge were more balanced. Even though $31.3 \%$ of the students stated that knowledge acquired during secondary schools was useful to understand the subject content most of the time, $27.9 \%$ responded as half of the time and $21.9 \%$ little of the time. The majority of the students said that they have learned to make connection between different subjects $38.5 \%$ only half of the time.

\section{Learning style preferences}

Table 1 shows the distribution of the learning style preferences among the first year medical students. The majority of them, 59.89\% (115) preferred multiple learning styles. Bimodal study preference was predominant $31.2 \%$ compared to the quadrimodal preference $4.1 \%$. Aural/kinesthetic combination was the commonest $(41.7 \%)$ in the bimodal group; whereas, the visual/ aural/ kinesthetic combination was predominant $40.5 \%$ in the trimodal group.

Among the students with a unimodal study style preference $(40.2 \%)$, aural mode was the commonest $55.84 \%$ (43). Read/write and visual study styles showed the least preference representing $3.9 \%$ each, respectively (Table 1 ).

Table 1: Study style preferences among the first year medical students according to the VARK test

\begin{tabular}{llll}
\hline Unimodal & Bimodal & Tri-modal & Qadrimodal \\
$\mathbf{4 0 . 2 \% ~ ( 7 7 ) ~}$ & $\mathbf{3 1 . 2 \% ( 6 0 )}$ & $\mathbf{2 4 . 5 \% ( 4 7 )}$ & $\mathbf{4 . 1 \% ( 8 )}$ \\
\hline Visual 3.9\% (3) & Aural/Kinesthetic 41.7\% (25) & Aural/Read/Kinesthetic 38.3\% (18) \\
Aural 55.8\% (43) & Aural/Read 8.3\% (5) & Visual/Aural/Kinesthetic 40.5\% (19) \\
Read 3.9\% (3) & Read/Kinesthetic 3.3\% (2) & Visual/Aural/Read 12.7\% (6) \\
Kinesthetic 36.4\% (28) & Visual/Aural 15\% (9) & Visual//Read/Kinesthetic 8.5\% (4) \\
& Visual/Kinesthetic 26.7\% (16) & \\
& Visual//Read 5\% (3) & \\
\hline
\end{tabular}

Note: The numbers of the students are indicated within brackets following the percentage of the students representing particular study style preference or the combination $(n=192)$. 
Furthermore, the study style preferences between the genders were analyzed. Of the unimodal group some interesting differences were observed. Males preferred auditory mode
$27 \%$ more than females $16 \%$. The kinesthetic mode was preferred by the females $20 \%$ while males $11 \%$, (Figure 1). They were not statistically significant $(P=0.115)$.

Figure 1: Distribution of the unimodal study style preferences among male and female students

Females

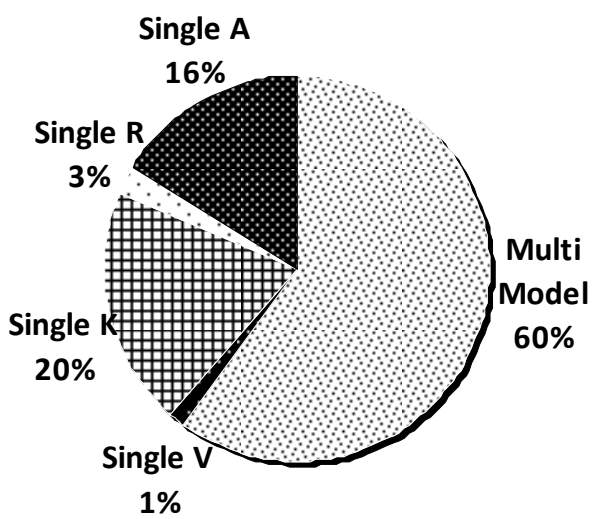

Males

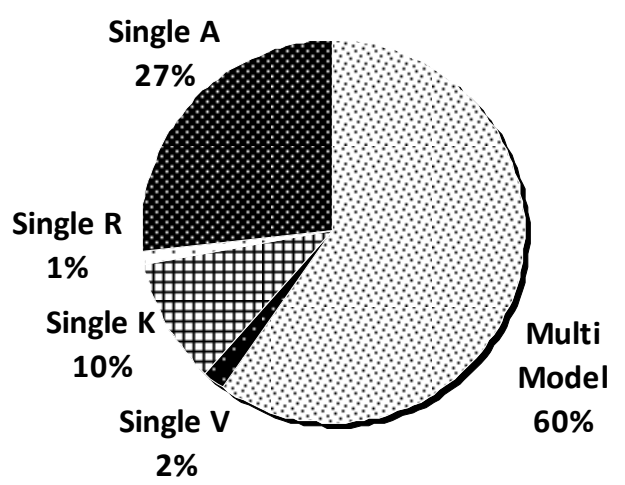

\begin{tabular}{lcccccc}
\hline Gender & Multimodal & $\begin{array}{c}\text { Single } \\
(\mathrm{V})\end{array}$ & $\begin{array}{c}\text { Single } \\
(\mathrm{A})\end{array}$ & $\begin{array}{c}\text { Single } \\
(\mathrm{R})\end{array}$ & $\begin{array}{c}\text { Single } \\
(\mathrm{K})\end{array}$ & $\begin{array}{c}\text { Total number of } \\
\text { students }\end{array}$ \\
\hline Male & 67 & 1 & 30 & 2 & 12 & 112 \\
Female & 48 & 2 & 13 & 1 & 16 & 80 \\
$\quad$ Total & 115 & 3 & 43 & 3 & 28 & 192 \\
\hline
\end{tabular}

Note: Percentage of each gender that preferred visual (V), auditory $(A)$, read/write $(R)$, or kinesthetic $(K)$ as their unimodal preference. The contingency table was used for the Chi-square test $(P=0.115)$. 
Approximately similar percentages of the males and females preferred multimodal learning style $60 \%$ and no significant difference was observed in the distribution among the multimodal groups (bimodal/ trimodal/ quadrimodal) $p=0.452$. The bimodal variety was slightly commonor among females $54 \%$ compared to males $50 \%$ (Figure 2 ).

Figure 2: Distribution of the multimodal study style preferences among male and female students
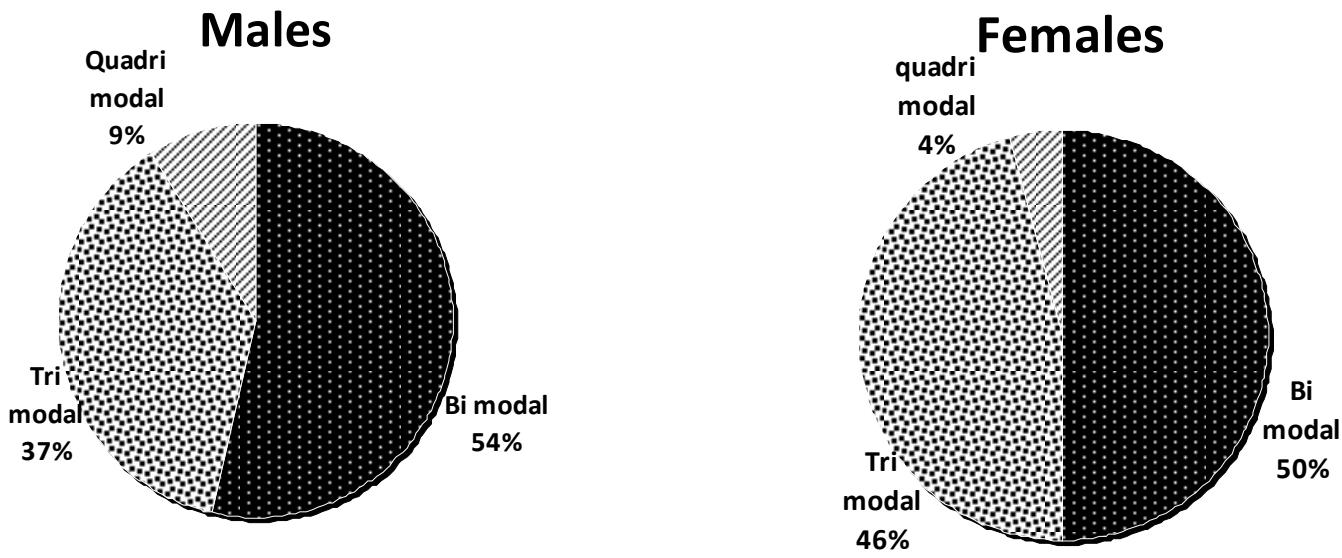

\begin{tabular}{lcccc}
\hline Gender & Bimodal & Trimodal & Quadrimodal & $\begin{array}{c}\text { Total number of } \\
\text { students }\end{array}$ \\
\hline Male & 36 & 25 & 6 & 67 \\
Female & 24 & 22 & 2 & 48 \\
$\quad$ Total & 60 & 47 & 8 & 115 \\
\hline
\end{tabular}

The contingency table was used for the Chi-square test $(n=115, P=0.452)$.

\section{Discussion}

This study was conducted among first year medical students in the Faculty of Medicine, University of Colombo to assess the perceptions of students about the current teaching strategies. It further assessed the predominant learning style preferences using the VARK questionnaire and the gender differences for learning style preferences.

According to the results the majority of students accepted both lectures and Small Group Activities were useful. However, more favourable answers had been given for the Small Group Activities. This highlights the importance of giving more emphasis to Small Group Activities. Not only does it match with the learning styles of the multimodal learners; it promotes ability of working in groups and generates high level of motivation and enthusiasm. For medical students, who will always be working in team environments as future doctors, these exposures are invaluable as suggested by some authors (Lujan, 2006; Baykan, 2007). But we suggest lectures must also go hand in hand not as a mode of passive information delivering, but as a way of guiding students for self-learning with more teacher student interactions. Students were not satisfied with the feedback they receive during the learning activities. We believe it is important to provide students with feedback during Small Group Activities so students can correct themselves before the assessment.

Diverse responses were obtained for the integration of knowledge. Students should be encouraged to develop this skill which is important in the future as practicing doctors. Active learning strategies such as Small Group Activities should be used to promote integration of knowledge. For example, case scenarios can be incorporated into group work, so students can discuss between different subjects which will stimulate deep learning.

Our results showed that the majority of the students preferred multimodal learning (60\%). They were in an agreement with other studies (Lujan, 2006; Meechan-Andrews, 2009; Baykan, 2007; Breckler, 2009; Murphy, 2004). 
Figure 3: Comparison of specific multimodal preferences with the literature

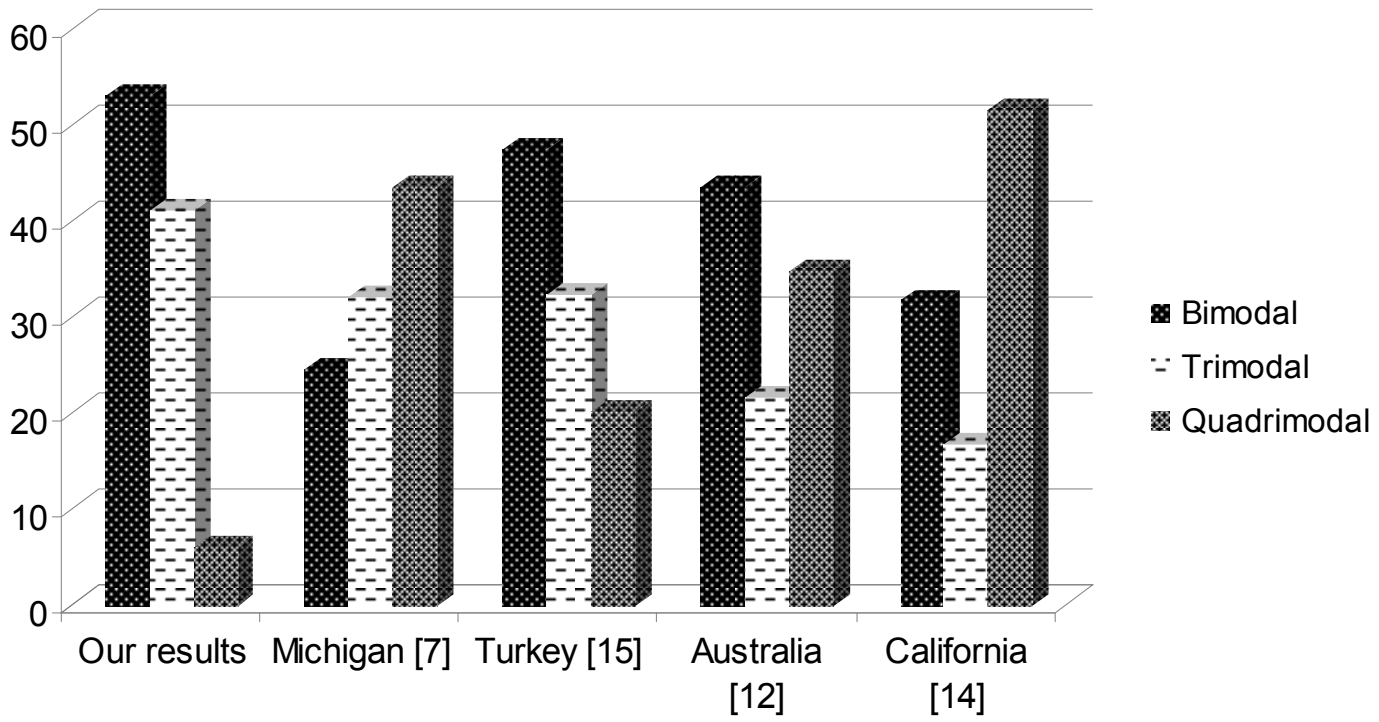

Note: Comparison of the multimodal preferences between different studies [7, 12, 14, 15]. Percentages have been calculated to the total number of multimodal learners.

It is obvious that the physically normal students generally preferred information using all their senses (Slater, 2007). Even though some students have been categorized as unimodal; they use all senses other than their dominant mode to a variable degree. Multimodal learners may have a special advantage during learning to grasp new information quite efficiently using several of their senses. Our findings highlight the importance of employing a variety of teaching techniques to tally with the learning needs of medical students. Several studies have shown a positive correlation between students' achievements with the matching of learning styles (Mangino, 2003; Rochford, 2004). In contrast, some have suggested that the deliberate mismatch can cause students' boredom and subsequent disengagement with learning. As the majority of the students are multimodal learners, teachers have the opportunity to provide them with a combination of teaching methods where students can choose on their own.

Our results have shown that the majority of the multimodal learners are bimodal $31 \%$, quadrimodal $4.1 \%$ compared to other studies where the distribution is more balanced (Figure 3). Even though, our students are multimodal learners they seem to be restricted to two combinations most of the time. This makes the task difficult for the educators when selecting learning strategies for all students. It is said that students will only remember $20 \%$ of what they read, $30 \%$ of what they hear, $40 \%$ of what they say and $60 \%$ of what they do. This percentage increases up to $90 \%$ for information they say, hear, see and do (University of Newcastle. Study Skills Guide, 2011). Therefore, most students may benefit from active learning strategies over the traditional lecture format, because they reach all types of learners in the visual, auditory, reading/writing and kinesthetic schemes (Lujan, 2006). We suggest that recent advances like use of podcasts for auditory learners, the use of audience response systems for kinesthetic learners and the development of electronic learning packages such as reusable learning objects for visual learners may help and further research should be carried out to find out the right combinations.

Comparison of the unimodal preferences has shown interesting results, where our students were more auditory learners compared to kinesthetic in previous studies (Figure 4). Their learning styles could have been influenced by the primary and secondary education which is more or less teacher-oriented one way learning process that promotes auditory learning. Unimodal students prefer one of the modalities over the other three so strongly and which is unique to different student populations (Figure 4). This highlights the importance of assessing learning styles among different subsets of medical students. 
Figure 4: Comparison of the unimodal preferences with the literature

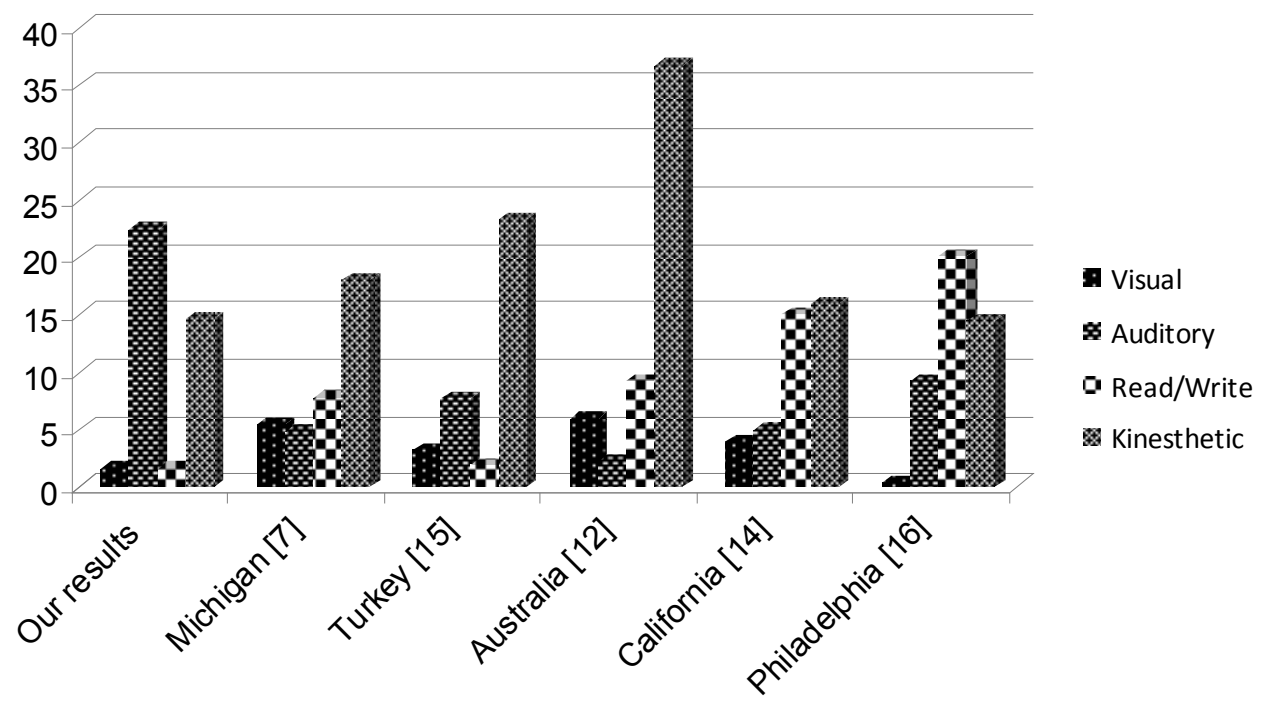

Note: Comparison of the unimodal preferences between different studies [7, 12, 14 -16]. Percentages have been calculated to the total number of students.

There were no significant gender differences in the learning styles of students as shown in previous studies (Slater, 2007; Baykan, 2007). However, males preferred auditory mode more than females when comparing unimodal learning style preferences. In contrast, previous studies have shown that the male students primarily preferred to use tactile resources to learn new information (Slater, 2007; Jorge, 1990]

\section{Limitations}

This study is limited to a single faculty and a single year of students with a limited, yet a diverse student population. Therefore we may not able to generalize the findings. VARK questionnaire does not account for compounding factors such as socioeconomic status, race, and culture etc. It remains as a drawback in this study.

\section{Conclusions}

In summary, our results have shown that a majority of the students are multimodal learners. There was no significant gender difference observed for learning styles. Positive responses were obtained for the Small Group Activities and lectures. Therefore active learning should be further encouraged during Small Group Activities as well as in lectures, using a variety of learning tools such as video clips, computer simulations and interactive models. A feedback should be provided to the students during learning sessions. Recent advances podcasts for auditory learners, audience response systems for kinesthetic learners and the development of electronic learning packages such as reusable learning objects for visual learners should be encouraged.

\section{Competing interests}

The authors declare that they have no competing interests.

\section{References:}

Baykan, Z. \& Nacar, M. (2007) Learning styles of first-year medical students attending Erciyes University in Kayseri, Turkey. Adv Physiol Educ, 3, pp.158-160.

Breckler, J. Joun. D. NGOH (2009) Learning styles of physiology students interested in the health professions. Adv Physiol Educ, 33, pp. 30-36.

Coffield, F., Moseley, D. \& Hall, E. Ecclestone K. (2004) Learning Styles and Pedagogy in Post16 Learning: a Systematic and Critical Review. Learning Skills and Research Centre, London.

Coffield, F., Moseley, D., Hall, E.\& Ecclestone, K. (2004) Learning styles and pedagogy in post16 Learning: a systematic and critical review. Learn Skills Res Centre, London.

Fleming, N.D. 1995, 'I'm different, not dumb: modes of presentation (VARK) in the tertiary classroom' Proceedings of the 1995 Annual Conference of the Higher Education and Research Development Society of Australasia (HERDSA), Edited by Zelmer A. Research and development in higher education, pp. 308-313. 
Fleming, N.D 2001, VARK, A Guide to Learning Styles. [Online], Available at: http://www.vark learn.com/english/page.asp?questionnaire. [Accessed 22 December 2010] .

Fleming, N.D 2001, VARK, A Guide to Learning Styles. [Online], Available at: http://www.varklearn.com/english/index.asp [Accessed 22 December 2010].

Gudmundsdottir, S. \& Shulman, L. (1987) Pedagogical content knowledge in social studies. Scand J Educ Res, 13, pp. 59-70.

Honigsfeld, A.M. (2001) A comparative analysis of the learning styles of adolescents from diverse nations by age, gender, academic achievement level and nationality (Doctoral dissertation). Dissert Abstr Int, 62, pp.969.

Jorge, F. (1990) A comparison of learning style preferences between seventh - and eighth grade students (Doctoral dissertation). Dissert Abstr Int, 51, pp. 3365A.

Keefe, J.W. (1987). Learning style: theory and practice. VA: National Association of Secondary School Principals, Reston.

Lujan, H.L. \& DiCarlo, S.E. (2006) First-year medical students prefer multiple learning styles. Adv Physiol Educ, 30, pp. 13-16.

Mangino, C. \& Griggs, S. (2003) Learning styles in higher education. In Synthesis of the Dunn and Dunn Learning Styles Model Research: Who, What, When, Where and So What-the Dunn and Dunn Learning Styles Model and Its Theoretical Cornerstone. St. John's University, New York.
Meechan-Andrews, T.A (2009). Teaching mode efficiency and learning preferences of first year nursing students. Nurse Educ Today, 29, pp. 24-32.

Miller, P. (2001). Learning styles: The multimedia of the mind (ED 451340).

Murphy, R.J., Gray, S.A., Straja, S.R.\& Bogert, M.C. (2004). Student learning preferences and teaching implications. J Dent Educ, 68, pp. 859-866.

Rochford, R. (2004). Improving academic performance and retention among remedial students. Community College Enterpr, 10, pp. 23-36.

Slater, J.A., Lujan, H.L. \& DiCarlo, S.E. (2007). Does gender influence learning style preferences of first-year medical students? Adv Physiol Educ, 31, pp. 336-342.

Tuan, N.V. (2005) Higher education: Encouraging and sustaining desire of learning. Sai Gon Giai Phong, 3.

University of Newcastle. Study Skills Guide. [Online], Available at: http://www.ncl.ac.uk/students/well being/assets/documents/StudySkillsGuide.pdf. [Accessed 10 January 2011]. 